\title{
0 corpo cómico em Esse tal alguém, de Teresa Rita Lopes
}

\author{
Lucas Cureau
}

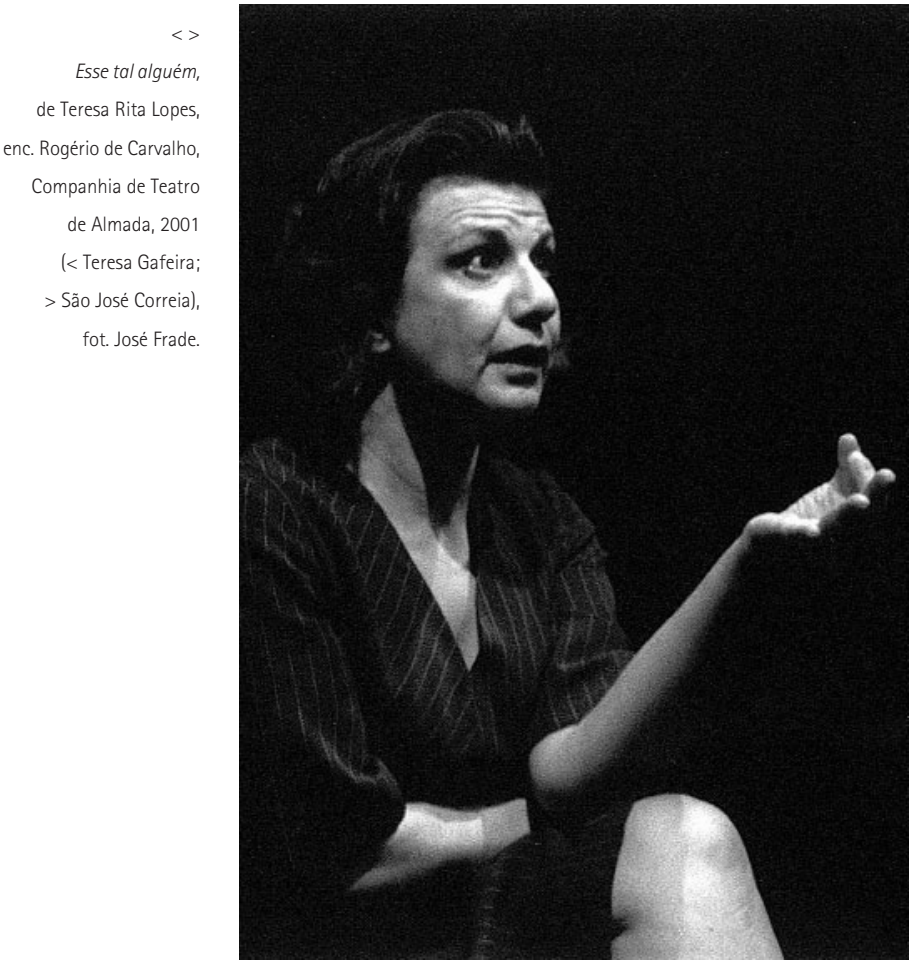

Entre as recentes obras teatrais da já consagrada Teresa Rita Lopes, Esse tal alguém aparece como uma interessante sintese de várias vertentes que podemos encontrar no conjunto de sua obra. Dentro do teatro português contemporâneo, esta obra heterogénea guarda uma unidade geralmente legitimada pelo seu rigor, pela sua originalidade, ou por seu lirismo altamente inventivo e feminino, ou até mesmo feminista.

No prefácio de seu Teatro reunido, a organizadora Sebastiana Fadda classifica de forma brilhante as diferentes tendências do teatro lopesiano, num esforço de tematização e de generalização cuja pertinência não carece de ser demonstrada, parecendo-nos

particularmente perspicaz na sua conclusão. Trata-se, no teatro de Teresa Rita Lopes, de "tornar habitáveis o corpo o quotidiano e o mundo" (Fadda 2007: 19). Posicionandonos aquém desta interpretação vagamente pósexistencialista, tentaremos elaborar análises mais formais acerca do problema do corpo cómico e do corpo cénico estabelecendo novos paralelismos e inserindo a "visão de mundo" da autora num conjunto mais largo de conceitos e paradigmas.

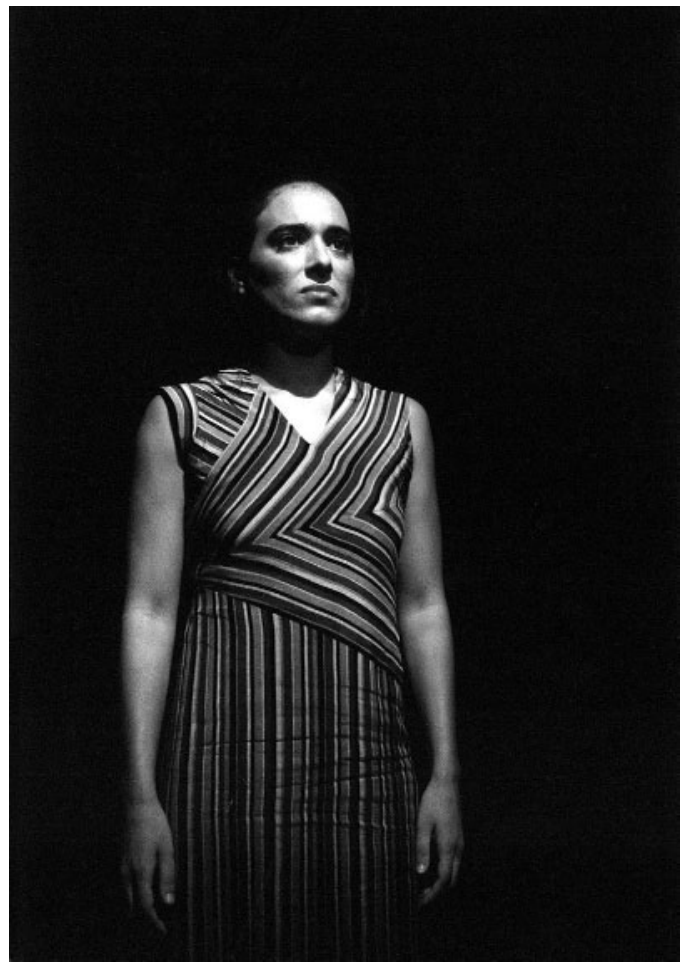

Primeiramente, questionaremos as formas e as funções do texto dramatúrgico lopesiano, analisando sobremodo as noções literárias (e linguisticas) de género intertextualidade e interlocução. Em seguida, veremos como se coloca na peça analisada o problema da imagem, duplamente relacionado com o problema da mistificação romântica e com a questão do espaço cénico. Tal concepção, a nosso ver, afirma uma visão neo-barroca do mundo, cujo raio de alcance não se limita ao âmbito do teatro contemporâneo. Por fim, tentaremos definir uma poética da invenção que somente a palavra feminina torna possivel, bem como as relações que tal palavra entretém com um corpo cénico que é também maneira de contar.

1.

A presença da poesia no teatro, em termos puramente formais, apresenta-se principalmente como uma reapropriação da tragédia grega. Em seu "Modo de usar", a autora é explícita ao configurar os seus dois semi-coros: o primeiro, feminino, é "lírico"; o segundo, masculino, é discursivo e "sentencioso". 
0 que aproxima ou distancia essa configuração inicial da tragédia grega clássica? Tomando por modelo a tragédia sofocliana, Aristóteles afirma na sua Poética que o coro deve ser considerado como um verdadeiro actor do "drama" (entendido como "acção"), cabendo-Ihe a função de participar no desdobramento dramático da intriga. Em Esse tal alguém, a forte heterogeneidade das cenas torna essa participação propriamente impossivel: os semi-coros comentam mais do que articulam a dramaticidade da peça. Apresentandose como dois coros "pela metade", as duas instâncias dramáticas não simbolizam apenas o que pode haver de antagónico ou complementar entre homem e mulher, entre ELE e ELA. Formalmente, ambos os grupos são amputados de sua função dramática original. Exemplo irrefutável de tal transformação: em nenhum momento da peça trazem alguma informação determinante para os relatos do que Ihes sucede, antes explicitam os fundamentos conceptuais do conjunto da obra, numa dinâmica mais estrutural do que linear.

No que diz respeito à narrativa, dificilmente encontramos uma tradição teatral fortemente ancorada numa relação explícita entre narração e teatro. Parece-nos importante então, acentuar o delicado pleonasmo anunciado no arquitexto da obra: "ficção dramatizável". Esse tal alguém questiona, de facto, o conceito de "acção dramática" e, seguindo as tradições populares dos "contadores de histórias" e dos espectáculos de feira (universo simbólico anunciado desde a primeira cena), a voz que conta assume diferentes papéis.

Fazendo da noção de "intriga" o elo entre a realidade histórica (que precisa de ser contada e utiliza meios ficcionais para se tornar inteligivel) e a ficção (que precisa ser temporalizada para significar), Paul Ricoeur reinterpreta, em Du texte à l'action, a poética aristotélica segundo a óptica da configuração narrativa e temporal. Se, no texto de Rita Lopes, "drama" se refere ao género teatral consagrado pela ideologia burguesa e romântica (e seu individualismo "sem Deus"), uma leitura atenta do filósofo francês permitenos dizer que, tanto na narrativa como no teatro (na ficção como no drama), trata-se sobretudo de atribuir uma temporalidade à acção, por meio de procedimentos inteligiveis. Tornando ELE e ELA arquétipos de um mesmo drama humano, T. Rita Lopes recorre à narrativa para criar uma tensão e uma redundância que afirmam a possibilidade de dramatizar toda a experiência humana.

2.

Que forma toma a acção dramática em Esse tal alguém?
Mais precisamente, que modelo de intriga nos é proposto por Teresa Rita Lopes, e sob que formas este modelo se apresenta? Em todas as cenas, trata-se evidentemente de contar histórias de amor mais ou menos fantasiosas, mais ou menos bem resolvidas.

Dois mecanismos correlatos parecem estruturar a intriga da peça, organizando histórias de amor quase sempre ambivalentes (leia-se: histórias de amor que sempre tomam duas vias diferentes). Primeiramente, um dos elementos estruturais mais relevantes é a intertextualidade interna à organização das cenas. À cena 2, na qual um homem casado se apaixona por uma mulher de calendário, corresponde dramaticamente a cena 7, na qual uma mulher casada defende frente ao "Senhor Doutor Juiz" a sua anacrónica paixão pelo "homem do quadro". Formalmente, esta mesma cena 7 retoma a cena 4, na qual um homem se dirige à mesma figura de autoridade que é o "Senhor Doutor Juiz". Tematicamente, esta mesma quarta cena coloca em jogo o arquétipo do romântico facilmente lírico (que faz "versos" e não "poesia") e dificilmente físico (que tem vergonha do próprio corpo), já presente na cena anterior. Seguindo o mesmo critério de encadeamento pela caracterização da personagem, a mulher em busca de "uma casa e desse tal alguém" da cena 5 é anunciada pela figura feminina da cena 4 , que também vê no amor uma coisa a ser construida e não somente desfrutada. Seja pela noção de personagem e suas diferentes configurações (arquétipo, figura), seja pelo desdobrar dramático das cenas, Esse tal alguém estrutura-se em constante referência aos seus próprios mecanismos internos de "significação".

A esta intertextualidade interna, podemos no entanto acrescentar uma intertextualidade pela qual a autora se refere a grandes textos do repertório teatral clássico ou moderno. Sempre no intuito de fortalecer uma intriga que o texto teatral mais escamoteia do que nega, vemos assim intervirem em Esse tal alguém intrigas de outras peças consagradas. Na segunda cena, por exemplo, o monólogo masculino retoma não somente o cenário da peça 0 barbeiro de Sevilha, de Beaumarchais, mas também a acção dramática que estrutura a intriga da mesma: como na obra do dramaturgo francês, trata-se de roubar a mulher amada ao "velhaco" que a detém. Este mesmo desdobramento dramático, vindo de Escola das mulheres de Molière, não encontra na figura da esposa do barbeiro uma personagem à altura de Fígaro, é certo; tampouco guarda o mesmo teor político e social das peças às quais se refere. No entanto, no que diz respeito à intriga, uma 
analogia dessa ordem parece-nos justificada em vários outros espectros temáticos: a questão da espera (e sua desaceleração dramática) evoca o teatro do absurdo e a dramaturgia de Samuel Beckett ( $\dot{A}$ espera de Godot); o problema do sonho e da ilusão convoca a mais pura tradição do teatro barroco espanhol, que encontra nas figuras de Calderón de la Barca ( $A$ vida é sonho; "será toda a vida um faz-de-conta?", Semi-coro 2, entreacto 1, p. 17) e de Lope de Vega, representantes privilegiados de uma filosofia teatral reapropriada. Este mesmo Lope de Vega teoriza uma comédia espanhola cujos fundamentos não passam desapercebidos em Esse tal alguém: privilegiando o sujeito à acção e à caracterização da personagem, uma acção não conforme às normas antigas que possa cativar o seu público, Teresa Rita Lopes afirma mais uma vez o seu gosto por intrigas rebuscadas.

De maneira indirecta, esta intertextualidade propriamente teatral coloca sobre a mesa o problema dramatúrgico do repertório. No palco, a história por contar deve ser nova, adequada às expectativas e ao universo de um público contemporâneo? Ainda é possivel interpretar textos datados, marcados pelas épocas em que foram escritos? Inserindo o repertório teatral na própria composição de sua obra, a autora portuguesa toma uma posição mais nuançada, que problematiza internamente essa questão da possibilidade de encenação.

3.

Embora responda a critérios de dramaticidade ambíguos (articulação da intriga pela redundância da narração) e se insira numa dupla intertextualidade igualmente dramática a forma do monólogo coloca também de maneira pungente a questão linguistica do interlocutor. De que maneira se fala com o "Outro" em Esse tal alguém?

Já no primeiro entreacto, o problema coloca-se de maneira explícita, pela voz do semi-coro feminino: "Ouem és tu, esse tu com quem falo?" (p. 15). No entreacto quinto, o mesmo semi-coro declina este questionamento de maneira mais radical, posicionando-o entre as figuras do "homem" e de "Deus": "Ouem és, esse a quem eu digo tu?" (p. 60). Problema crucial da linguistica inaugurada por Ferdinand de Sausurre, o interlocutor é, segundo Émile Benveniste, o imperativo de todo e qualquer enunciado: sem interlocutor nenhuma linguagem se actualiza. De um ponto de vista mais filosófico, Jacques Derrida afirma em seu 0 monolinguismo do outro que a nossa maneira de falar é por definição configurada pela instância do outro. Em Esse tal alguém, esta instância é apresentada como um mistério, retomando externa e internamente problemas colocados por autores como Samuel Beckett, que, em Actos sem palavras, experimenta a supressão da fala como novo elemento dramatúrgico, questionando e

reconfigurando a relação entre o espectáculo e o público. De que maneira um questionamento desta ordem aparece na peça lopesiana?

Tematicamente, aparece pelos comentários acima citados. Nos entreactos, os semi-coros não somente comentam e estruturam a obra, como também colocam em jogo uma alteridade reciproca e difícil, mais fundamentada por suas diferenças do que por seus pontos comuns. Interpretando diferentemente a acção que se desdobra sob seus olhos, ELE e ELA repartem-se também no modo como se relacionam com o "Outro": a figura feminina é lírica na sua forma e conteúdo (utilização do verso livre contemporâneo para expressar uma visão bem personalizada das relações humanas: é necessário construílas); já a figura masculina usa as formas populares mais tradicionais, para evocar ópticas mais comuns e menos individualizadas. Deste antagonismo temático e formal nasce uma tensão que as personagens da peça incorporam: duvidando da pertinência da relação (entenda-se por relação esse forte e necessário compromisso com a alteridade, enunciado por Édouard Glissant na sua Poética da relação III), as personagens femininas das cenas 4 e 5 postulam a necessidade individual de construir uma percepção de "esse tal alguém", nascido do mistério inicial - esta construção seria a única a poder criar uma relação verdadeiramente recíproca. Negativamente, as personagens masculinas seguem critérios não relacionais, colocando à frente de tudo uma visão quase utilitária da relação.

Para retomar o problema da presença da imagem no texto, é importante sinalizar antes de mais nada que tal desdobramento evoca primeiramente a problemática da mistificação pela imagem. Na cena 2 em particular, uma visão satírica de certo idealismo banalmente romântico é firmemente apresentada, tomando as mais diferentes formas. A figura feminina é clara no que diz respeito à aura na qual o homem a envolve: "Só me queres para olhar" (p. 25). No entanto, mais do que uma simples sátira na qual se convoca um imaginário datado e pouco adaptado às situações dramáticas presentes, imagem e mistificação colocam de maneira palpável o problema fenomenológico e estético da visão. Na cena 4, ELA estipula que "primeiro temos que descobrir o que está à vista mas a gente não conhece porque só olha com os olhos" (p. 41). É possivel, portanto, "conhecer" pela visão? Caso seja possivel, de que maneira se adquire este conhecimento? Este último é perceptivo, sensorial, ou estrutural? Mais uma vez, é curioso notar a amplitude de tais questionamentos, que nos remetem para as mais diferentes áreas do pensamento crítico contemporâneo: para o teatro e para a representação (imagem e espaço cénico), obviamente, mas também para o problema da representação nas artes plásticas, assim como para os questionamentos psicanalíticos acerca dos mecanismos do sonho e para as suas relações com a produção textual.

No que diz respeito à imagem e mistificação (ao problema da visão no desejo e no relacionamento amoroso), a figura feminina estabelece uma relação que, principalmente a partir das cenas 4 e 5 , se apresenta como mediata: se a visão interfere no relacionamento amoroso, deve ser por meio de mediações e experiências sensoriais 


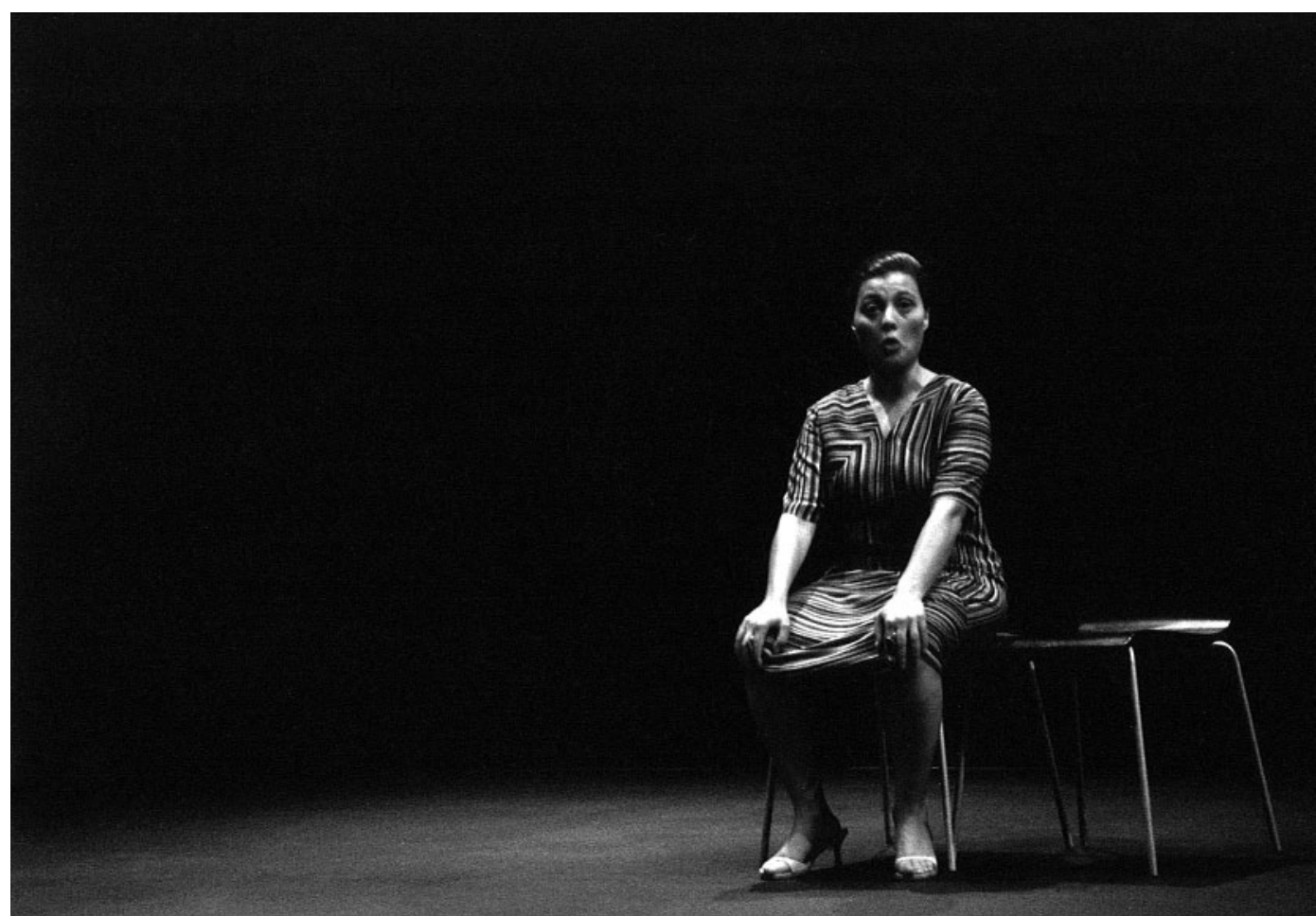

Esse tal alguém

de Teresa Rita Lopes, enc. Rogério de Carvalho, Companhia de Teatro de Almada, 2001 (Maria Frade), fot. José Frade. não imediatas, contrariamente àquilo que muitas vezes almejam as personagens masculinas (o vulcão, o deslumbramento, etc.)

Assim como evoca a questão do desejo e da imagem (e as suas mistificações), a tensão estabelecida por esse "desejar sem tocar" (semi-coro feminino, entreacto 4) trabalha sobre a relação entre espaço cénico e representação. Em On n'y voit rien, o historiador da arte francês Daniel Arasse problematiza a representação pictural sob o mesmo ângulo: um quadro "dá vontade" de tocar, mas apresenta-se precisamente como aquilo que não pode ser tocado. Colocando o público como interlocutor privilegiado da representação teatral através da forma do monólogo, radicalizando uma posição por vezes ingrata (referimo-nos à arma apontada aos espectadores na cena 6), Teresa Rita Lopes articula um "muro invisivel" (aquilo que separa a peça do público) cujas fronteiras são opacas e ambivalentes. 0 público pode desejar aquilo que lhe é representado, sem nunca poder tocar. No entanto, o que está em jogo do outro lado do muro é precisamente isto, assimilando-se assim mais uma vez vida e teatro. Como construir um espaço cénico que seja também espaço vital? Na peça Who's Afraid of Representation?, apresentada em 2006 no Festival Alkantara (Lisboa), Rabih Mroué retoma de forma violenta essa assimilação, perguntando já no título de sua obra: "quem tem medo da representação?" Maneira de dizer, talvez, que o problema da representação teatral não se coloca apenas em termos teatrais, e que todo o universo dramático estabelece inúmeras pontes entre "realidade" e "ficção", entre texto e imagem, entre corpo e palavra.

A nosso ver, esta abordagem do problema representacional e cénico encontra uma base teórica em determinados mecanismos psicanalíticos identificados por Sigmund Freud. Posto que, se pensado nestes termos, todo o desejo acusa uma privação, é necessário construir (psiquicamente, mas também teatralmente) algo para substituir essa falta. Na cena 5, um pensamento desta ordem é claramente enunciado pela narradora-personagem, que evoca uma possivel cena fundadora no seu passado infantil, sob "os tectos maternos". Já no primeiro entreacto, a instância do "Outro" é trabalhada pelo semi-coro feminino de maneira explicitamente psicanalítica: "Quem és tu, que me obrigas a sonhar contigo?" (p. 15). Se o "Outro" se apresenta como um mistério, é precisamente porque nos obriga a dar sentido às imagens que nos são indirectamente inteligiveis, como o desejo ou o sonho freudianos. Sistemas imaginários (produtores de imagens), por definição indeterminados e desconhecidos, sonho e desejo levamnos a produzir textos ou representações que os tornem perceptiveis ou até mesmo assimiláveis. É importante notar, nesta perspectiva, que o recurso aos modelos psicanaliticos permite ultrapassar os paradigmas pessoanos de alteridade. Grande especialista do poeta Fernando Pessoa, Teresa Rita Lopes perverte assim o "teatro estático" do mesmo: fundamentado numa ausência de acção física, de inspiração simbolista (segundo a qual o espirito,

independente do corpo, seria intenso por ser incorpóreo), a poesia pessoana dramatiza interiormente a questão do "Outro", ficando portanto aquém da questão do corpo e da presença cénica.

As marionetas, neste contexto, expressam talvez a não-dominação do corpo à qual todo o ser humano pode estar submetido. Mais do que simples tradição popular, estes corpos mecânicos (brilhantemente trabalhados por autores como Heiner Müller, em Germania, Mort à Berlin: "Sur la scène se tient un homme. Il est plus grand que nature, peut-être une marionette" (1985: 98), as marionetas colocam o corpo humano (e portanto o corpo cénico) num outro âmbito. Nas suas Meditações cartesianas, o fenomenologista Edmund Husserl conceptualiza um corpo de "carne" que nos obriga a pensar a noção de corpo também a partir do sujeito que faz a experiência do mesmo. Mais do que por simples influência psicanalítica, a presença 


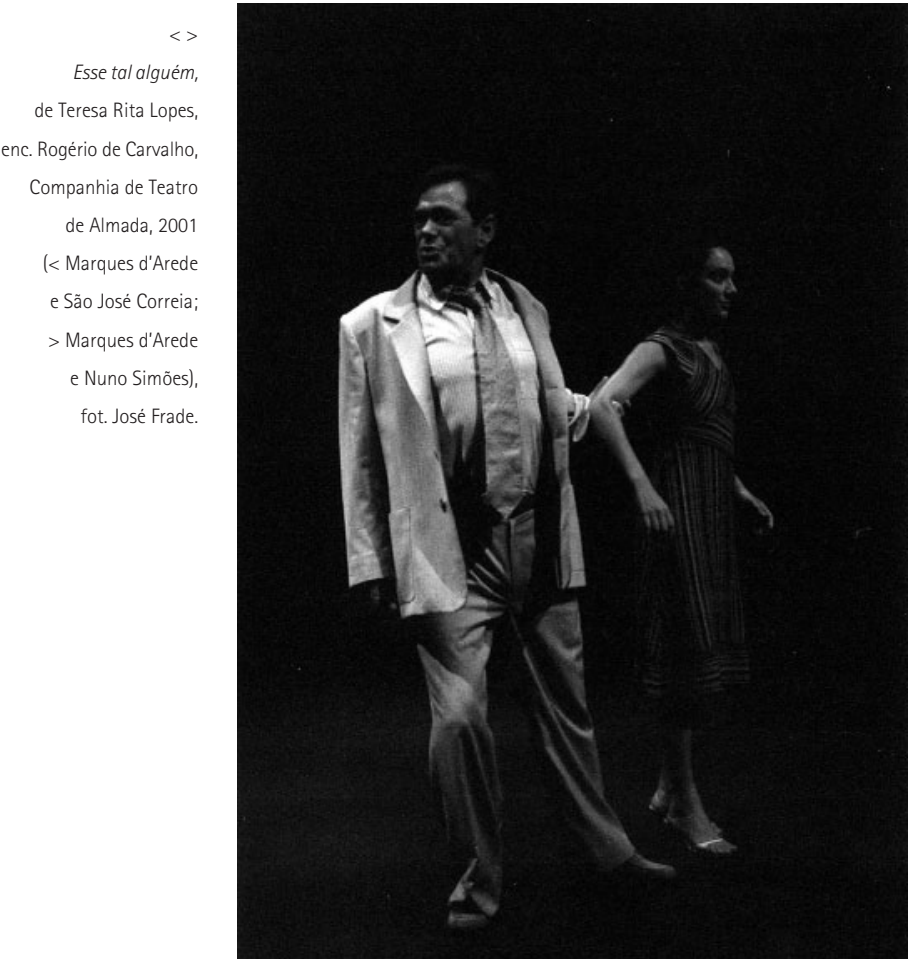

do corpo cénico em Esse tal alguém responde a uma larga criteriologia contemporânea, segundo a qual a instância corporal não pode ser plenamente objectivada e exteriorizada.

4.

Neste contexto teórico e conceptual, quais podem ser as funções do "corpo cómico" herdado da tradição farsesca? Em A cultura popular na Idade Média e no Renascimento, Bakhtin analisa a farsa e o Carnaval como inversões quase institucionais das normas políticas e sociais vigentes.

Género especialmente prolífico nessa cultura ibérica que o sociólogo brasileiro Sérgio Buarque de Hollanda julga essencialmente personalista (ao individuo socializado de outros paises europeus - e principalmente protestantes - corresponde o culto da pessoa em países como Espanha e Portugal), a farsa inverte em Esse tal alguém as prerrogativas românticas do amor. Satirizando o gosto do absoluto de tal concepção, Teresa Rita Lopes assimila na cena 2 a felicidade neste caso almejada ao simples alivio. Outro lado da moeda, aos versos responde a necessidade incontrolável de espirrar, ou ainda, de encontrar um canto onde poder mijar tranquilamente. Negando que o desejo seja coisa imediata e masculina, a autora estabelece que este gosto do absoluto se acompanha de uma nãoconsciência do corpo, cujas consequências não podem ser menos do que catastróficas.

No entanto, mais do que uma simples inversão grotesca do corpo cómico, o teatro lopesiano postula a variabilidade constante do corpo cénico, no espaço que lhe cabe. Metaforicamente, a "casa" almejada na cena 5 corresponde também a uma adequação necessária entre o espaço e o corpo. Embora resulte desta busca uma inegável frustração (a narradora-personagem não encontra a casa tão sonhada), trata-se explicitamente de colocar os mecanismos do sonho e do desejo ao serviço de uma construção espacial adequada. Podemos entender também o corpo

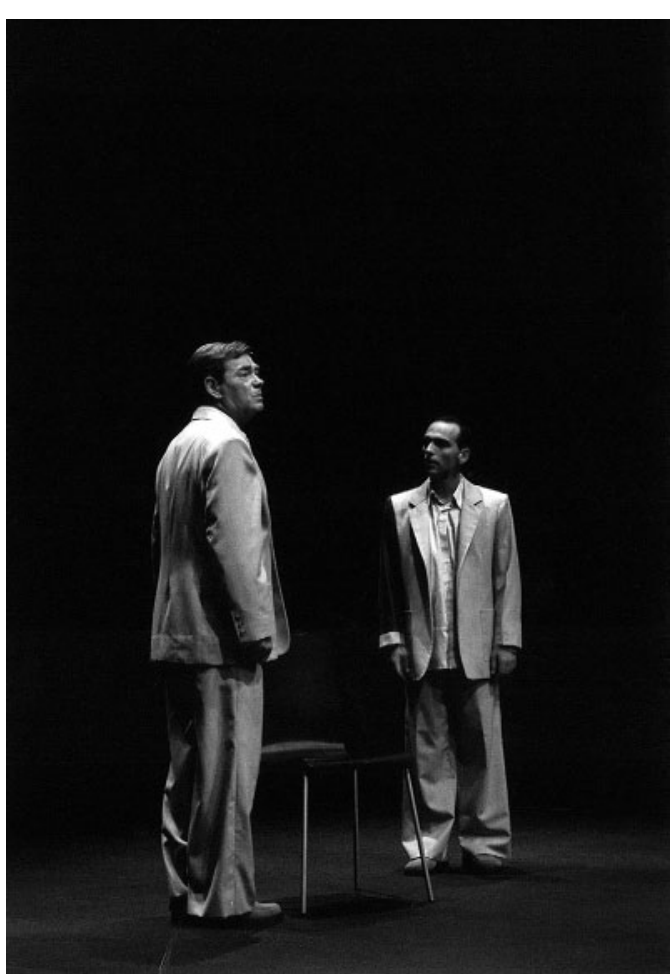

cénico como uma busca dessa adequação ao espaço que é o seu. Mais do que uma simples interpretação aplicada ao campo do teatro, tal concepção do espaço responde a uma criteriologia largamente sedimentada no pensamento crítico contemporâneo. Noutro pais, noutra língua, falando de outra arte - a escultura -, Georges Didi-Huberman estabelece em Etre crâne a necessidade de se pensar a arte em relação ao seu espaço - sendo este, igualmente, cosa mentale. Em seus Points de suspension, o encenador inglês Peter Brook analisa de maneira pouco teórica mas altamente empírica a questão do espaço cénico. Para Brook, este é antes de mais nada uma "ferramenta" de encenação. Embora longe do minimalismo cénico deste encenador, Teresa Rita Lopes traz à cena o problema do espaço teatral, e das diferentes maneiras de o ocupar.

5.

Definido o espectro morfológico da cena, torna-se então necessário analisar o lugar ocupado pela palavra dramática em Esse tal alguém. Antes de mais nada e mais uma vez, é preciso relacioná-la com o problema da poesia e com a oposição fortemente afirmada de uma palavra lírica feminina e um falar popular masculino.

Ao longo da peça, esta oposição encontra na dicotomia verso/poesia a sua maior expressão. Na cena 3, Teresa Rita Lopes cria deliberadamente uma tensão entre palavra poética e verso, entre indefinição e definição. Quando lisonjeada, a personagem feminina diz ao seu interlocutor masculino: "Adorei aquele verso em que me chama deusa do crepúsculo! Você é mesmo um poeta!" (pp. 31-32). Definição banalmente romântica da musa - mas, antes de mais nada, definição. Nesta mesma cena, quando revoltada, ELA diz que ELE Ihe escreve "baboseiras nas cartas" (p. 30). Questionando a própria pertinência do verso (tradição poética largamente problematizada pelo modernismo), a personagem feminina postula 
indubitavelmente algo que a ultrapassa. Na concepção lacaniana do desejo, este é precisamente o que não pode ser nomeado, aquilo que permanece indefinido. Formalmente, a palavra poética aparece portanto como algo que vai além do verso, algo que acontece num "teatro do acontecer" ao qual corresponde também um viver interpretado sob um ângulo barroco. Sendo precisamente aquilo que faz o desejo acontecer, a palavra poética (forma pela qual repetidas vezes a fala se dá a entender sobre a cena) responde a um paradigma ambíguo e complexo, que postula a sua impossibilidade para se tornar algo construído de maneira intimista e personalizada.

Figura explicitamente "feminilizada" (ele declara que não quer morrer sem "dar à luz" o poema), o amigo da narradora-personagem na cena 5 almeja escrever o poema de sua vida - e não o verso - encontrando dificuldades que colocam a poesia directamente no campo do inconsciente e do desconhecimento do mesmo. Exemplo privilegiado desta tensão: o escritor acaba escrevendo o poema "como o amor" quando menos se espera... Por outras palavras, escreve o poema como quem escreve um acontecimento fundador. Interpretação materna da palavra poética: esta acontece no corpo e no espaço do corpo, e não somente no espaço dentro do qual o dito corpo evolui (o escritor, por exemplo, não consegue escrever o "poema de sua vida" nas casas onde havia previsto fazê-lo).

Neste contexto, a invenção (interpretada como processo altamente feminino e variável - neste último ponto identificamos toda a influência de Fernando Pessoa na obra de Teresa Rita Lopes) torna-se o imperativo de toda e qualquer presença cénica. Passando pelo corpo, mas também pela palavra e pelo espaço variavelmente adequado aos dois critérios anteriores, a invenção tornase a única maneira para aprender a "brincar de incorporar personagens".

\section{6.}

Estruturada em constante referência aos seus próprios mecanismos internos, a peça Esse tal alguém reapropriase de um repertório teatral largo e variado. Sob diferentes formas, este último assume uma função narrativa e estrutural. Neste ponto, identificamos a erudição quase lúdica de Teresa Rita Lopes, erudição essa que traz consigo posições teóricas ambivalentes e nuançadas, que a autora muitas vezes reitera nos seus textos críticos.

Baseada numa oposição entre ELE e ELA, a peça trabalha sobre um paradigma relacional complexo: afirmando explicitamente a não concordância das perspectivas masculina e feminina, Teresa Rita Lopes traz indirectamente à cena a necessidade de uma relação baseada numa certa "complementaridade" - embora a instância feminina seja visivelmente apresentada como paradigmática.
Para além dos mecanismos psicanalíticos que obrigam homens e mulheres a dar sentido àquilo que vêem, o corpo cénico aparece em Esse tal alguém como algo variável e reversivel. Mais uma vez, nos parece necessário lembrar que, embora se relacione com a tradição farsesca ibérica assim como a uma visão do mundo fortemente aparentada ao barroco, este paradigma de presença cénica responde a uma criteriologia contemporânea largamente declinada noutros campos do conhecimento. Não podendo a instância corporal ser plenamente objectivada e exteriorizada, é preciso portanto pensar de que maneiras se pode ocupar um espaço - e, sobremodo, um espaço cénico.

Embora não possamos afirmar que uma dialéctica entre corpo e espaço seja positivamente corroborada pela autora (que muitas vezes parece acreditar mais no "fogo interno" de cada pessoa), parece-nos correcto dizer que o imperativo feminino e materno da invenção coloca o corpo em relação com o espaço, ainda que negativamente.

\section{Referências bibliográficas}

ARASSE, Daniel (2003), On n'y voit rien: Descriptions, Paris, Éditions Gallimard.

ARISTÓTELES (1997), Poétique, traduzido por Odette Bellevenue e Séverine Auffret, Torino, Éditions Mille et Une Nuits.

BAKHTIN, Mikhail (1993), A cultura popular na ldade Média e no Renascimento, São Paulo, Editora Hucitec

BENVENISTE, Émile (1966), Problèmes de linguistique générale, Tome I, Paris, Éditions Gallimard.

BROOK, Peter (1992), Points de suspension, trad. Jean-Claude Carrière e Sophie Reboud, Paris, Éditions du Seuil.

DERRIDA, Jacques (1996), Le monolinguisme de l'autre, Paris, Éditions Galilée.

DIDI-HUBERMAN, Georges (2000), Être crâne: Lieu, contact, pensée, sculpture, Paris, Les Éditions de Minuit.

FADDA, Sebastiana (2007), "0 teatro do Outro: Dramas singulares e plurais", Teresa Rita Lopes, Teatro reunido, vol. 1, Lisboa, Imprensa Nacional - Casa da Moeda.

GLISSANT, Édouard (1990), Poétique de la Relation. Poétique III, Paris, Éditions Gallimard.

HUSSERL, Edmund (1992), Méditations cartésiennes: Introduction à la phénoménologie, trad. G.Peiffer e E Levinas, Paris, Vrin.

LOPES, Teresa Rita (2001), Esse tal alguém: Ficção dramatizável, Porto, Campo das Letras.

-- (2007), Teatro reunido, Vol. 1, Lisboa, Imprensa Nacional - Casa da Moeda.

MÜLLER, Heiner ( 1985), Germania, Mort à Berlin, Paris, Les Éditions de Minuit.

RICOEUR, Paul (1986), Du texte à l'action, Paris, Éditions du Seuil. 